Kevin G. Hampel, MD

Roland D. Thijs, MD,

$\mathrm{PhD}$

Christian E. Elger, MD, $\mathrm{PhD}$

Rainer Surges, MD, PhD

Correspondence to

Dr. Surges:

rainer.surges@gmail.com

Editorial, page 756

Supplemental data at Neurology.org

\section{Recurrence risk of ictal asystole in epilepsy}

\section{OPEN}

\section{ABSTRACT}

Objective: To determine the recurrence risk of ictal asystole (IA) and its determining factors in people with epilepsy.

Methods: We performed a systematic review of published cases with IA in 3 databases and additionally searched our local database for patients with multiple seizures simultaneously recorded with ECG and EEG and at least one IA. IA recurrence risk was estimated by including all seizures without knowledge of the chronological order. Various clinical features were assessed by an individual patient data meta-analysis. A random mixed effect logistic regression model was applied to estimate the average recurrence risk of IA. Plausibility of the calculated IA recurrence risk was checked by analyzing the local dataset with available information in chronological order.

Results: Eighty patients with 182 IA in 537 seizures were included. Recurrence risk of IA amounted to $40 \%$ (95\% confidence interval [CI] 32\%-50\%). None of the clinical factors (age, sex, type and duration of epilepsy, hemispheric lateralization, duration of IA per patient) appeared to have a significant effect on the short-term recurrence risk of IA. When considering the local dataset only, IA recurrence risk was estimated to 30\% (95\% Cl 14\%-53\%). Information whether IA coincided with symptoms (i.e., syncope) or not was given in 60 patients: 100 out of 142 IAs were symptomatic.

Conclusion: Our data suggest that in case of clinically suspected IA, the recording of 1 or 2 seizures is not sufficient to rule out IA. Furthermore, the high short-term recurrence risk favors aggressive treatment, including pacemaker implantation if seizure freedom cannot be achieved. Neurology ${ }^{\circledR}$ 2017;89:785-791

\section{GLOSSARY}

$\mathbf{C I}=$ confidence interval; $\mathbf{I A}=$ ictal asystole

Ictal asystole (IA) is a rare but potentially devastating complication of epileptic seizures, affecting about $0.3 \%$ of patients with refractory epilepsy who underwent video-EEG monitoring. ${ }^{1}$ Most recent studies define IA as an RR interval longer than 3 seconds. ${ }^{1-3}$ IA can cause traumatic falls due to syncope with sudden loss of muscle tone. ${ }^{2-4}$ IA should not be diagnosed based on clinical grounds only, as its symptoms can easily be obscured by other ictal signs. ${ }^{2,5}$ Identification of IA, however, has important clinical implications, because the implantation of a cardiac pacemaker may prevent syncope-related falls and injuries. ${ }^{3,6}$ Therefore, simultaneous video-EEG and ECG is required to establish diagnosis when IA is clinically suspected. ${ }^{2}$ However, to date, the recurrence risk remains unclear and it is therefore not known how many seizures one should record in order to confirm or reject the clinical hypothesis of IA. ${ }^{7}$ In this study, we aimed to estimate the recurrence risk and potential influencing factors in patients with IA during simultaneous EEG and ECG recordings.

Department of Epileptology (K.G.H., C.E.E., R.S.), University Hospital Bonn, Germany; Stichting Epilepsie Instellingen Nederland-SEIN (R.D.T.), Heemstede; Department of Neurology (R.D.T.), Leiden University Medical Centre-LUMC, the Netherlands; and Section of Epileptology, Department of Neurology (R.S.), RWTH University Hospital Aachen, Germany.

Go to Neurology.org for full disclosures. Funding information and disclosures deemed relevant by the authors, if any, are provided at the end of the article. The Article Processing Charge was funded by the Verein zur Förderung der Epilepsieforschung e.V.

This is an open access article distributed under the terms of the Creative Commons Attribution-NonCommercial-NoDerivatives License 4.0 (CC BY-NC-ND), which permits downloading and sharing the work provided it is properly cited. The work cannot be changed in any way or used commercially without permission from the journal. 
METHODS Literature search strategy and data acquisition. We systematically reviewed the literature using the Preferred Reporting Items for Systematic Reviews and MetaAnalyses guidelines and the Patient Intervention/Exposure Comparison Outcome criteria. ${ }^{89}$ We used a combination of the following keywords: (1) arrest or asystole or syncope, (2) epilepsy, (3) human, (4) electrocardiogram or ECG or monitoring, and (5) electroencephalogram or EEG or monitoring. Publications were identified in 3 of the databases: PubMed (first date available to February 9, 2016), Web of Science (first date available to February 15, 2016), and ScienceDirect (first date available to February 1, 2016) (figure 1A). K.G.H. screened all titles and abstracts. K.G.H. and R.S. independently screened the 96 fulltext articles. Furthermore, a hand search of the reference lists and citation indices of these articles was performed. In addition, we searched our database at the Department of Epileptology (Bonn, Germany) for patients with IA during video-EEG or long-term EEG recordings from January 1, 1993, to December 31, 2015. If available, original records were reviewed; otherwise, data were taken from previously published case series from our center. ${ }^{10,11}$ IA was defined as RR interval longer than 3 seconds and at least twice as long as the previous $\mathrm{RR}$ interval. ${ }^{4}$ The inclusion criteria for the final analysis were (1) epilepsy patients with at least one IA simultaneously recorded with EEG and ECG, (2) more than one seizure simultaneously recorded with EEG and ECG, and (3) report of the total number of recorded seizures and IAs. Exclusion criteria were seizures induced by electrical stimulation (during presurgical assessment using intracranial EEG electrodes), intoxication, status epilepticus, subclinical seizures, nonepileptic events, pacemakers, and acute diseases like encephalitis. The study reporting was done in accordance with the Strengthening the Reporting of Observational Studies in Epidemiology statement guidelines. ${ }^{12}$

Standard protocol approvals, registrations, and patient consents. This work was carried out in accordance with the local ethics committee and the Declaration of Helsinki. Due to the retrospective nature, no informed consent was required.

Statistical analysis. We applied a random mixed effect logistic regression model using adaptive Laplace approximation to estimate the average recurrence risk of IA and to evaluate possible influencing factors. ${ }^{13}$ We have chosen to perform an individual patient data meta-analysis instead of a regular meta-analysis, as this approach allowed us to evaluate possible influencing factors on an individual patient level. ${ }^{14}$ The null model was used to estimate the average risk for recurrence of IA. As dependent variable we entered occurrence of IA as the binary outcome (1 indicating presence and 0 indicating absence of IA) into the model. As fixed effects, we entered sex, type of epilepsy (temporal or extra temporal), hemispheric lateralization (left, right, or bilateral), age, duration of epilepsy, and mean duration of IA per patient. In addition, we adjusted for the total number of seizures recorded per patient to control for a possible bias; this was because we observed a decreasing risk of IA with increasing numbers of recorded seizures per patients. As random effects, we included patients to account for nonindependence in the data (more than one seizure from the same patient). The variables were selected by forward and backward selection. Quantitative variables were

Figure 1 Preferred Reporting Items for Systematic Reviews and Meta-Analyses flow chart of search strategy and study selection

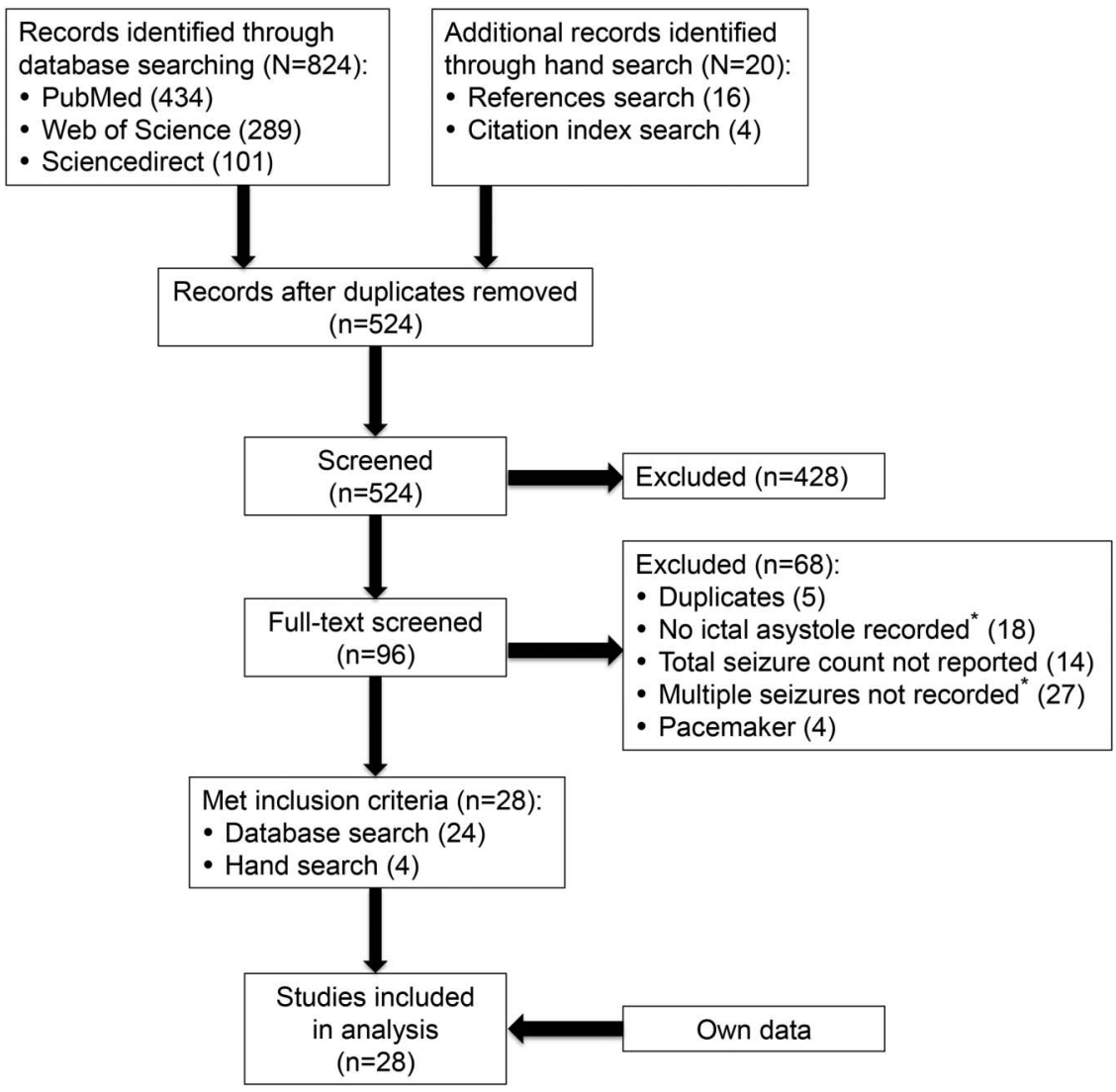

*With at least 1 ictal asystole and more than 1 seizure simultaneously recorded with EEG and ECG. 
handled as continuous data and missing data were handled by performing available-case analysis. In addition, to validate our results, we performed a regular random-effects meta-analysis using restricted maximum likelihood to estimate the average recurrence risk of IA. For most published cases, we lacked information on the chronological order of the seizures with and without IA. Therefore, we estimated IA recurrence risk by analyzing all seizures and IA including the index IA. To check for plausibility, we additionally calculated the IA recurrence risk using the local dataset from Bonn for which information on chronologic order was available. In this particular analysis, all seizures occurring before the index IA as well as the index IA (that led to the inclusion of the patient) were excluded from the calculation. Statistical analysis and graphical presentation were performed with $\mathrm{R}$ version 3.1.3 (R Foundation of Statistical Computation, Vienna, Austria).

RESULTS Selection process and search strategy. The comprehensive search strategy resulted in 844 articles (figure 1). After removing duplicates, 524 titles and abstracts were screened. We excluded 428 articles because they did not meet the inclusion criteria. Afterwards, we performed full text screening on the remaining 96 articles; from those, 68 were removed for the following reasons: 27 studies did not record or

\section{Table 1 Study characteristics}

\begin{tabular}{|c|c|c|c|c|c|c|}
\hline $\begin{array}{l}\text { Study } \\
\text { reference }^{a}\end{array}$ & $\begin{array}{l}\text { No. of } \\
\text { patients }\end{array}$ & $\begin{array}{l}\text { No. of } \\
\text { IAs }\end{array}$ & $\begin{array}{l}\text { No. of } \\
\text { seizures }\end{array}$ & $\begin{array}{l}\text { No. of } \\
\text { sIAs }\end{array}$ & Definition of IA & $\begin{array}{l}\text { Duration of } \\
\text { IA, s }\end{array}$ \\
\hline S1 & 1 & 5 & 9 & 5 & No & $8-21$ \\
\hline $\mathrm{s} 2$ & 1 & 4 & 13 & NR & No & $3-9$ \\
\hline S3 & 1 & 2 & 4 & NR & No & $\sim 16$ \\
\hline 16 & 9 & 25 & 55 & 14 & $\begin{array}{l}\mathrm{RR} \text { interval }>3 \mathrm{~s} \text { and } \geq 2 \text {-fold as the } \\
\text { previous one }\end{array}$ & $3-48$ \\
\hline S5 & 2 & 7 & 10 & NR & No & $10-96$ \\
\hline s6 & 1 & 3 & 3 & NR & No & $\sim 27$ \\
\hline s7 & 1 & 1 & 5 & NR & No & 8 \\
\hline S8 & 1 & 3 & 3 & NR & No & $8.5-24.5$ \\
\hline 7 & 5 & 9 & 30 & 5 & $\mathrm{RR}$ interval $>4 \mathrm{~s}$ & $4-36$ \\
\hline S10 & 1 & 2 & 3 & NR & No & 8-9 \\
\hline $\mathrm{S} 11^{\mathrm{c}}$ & 1 & 1 & 3 & NR & No & 4 \\
\hline S12 & 1 & 4 & 4 & 1 & No & $39-40$ \\
\hline S13 & 4 & 8 & 30 & NR & No & $9-25$ \\
\hline S14 & 1 & 2 & 2 & 2 & No & $8-10$ \\
\hline S15 & 1 & 1 & 5 & NR & No & 16 \\
\hline 2 & 9 & 26 & 103 & 26 & RR interval $>3 \mathrm{~s}$ & $3-25$ \\
\hline Own data & 9 & 15 & 32 & 5 & $\begin{array}{l}\text { RR interval }>3 \text { s and } \geq 2 \text {-fold as the } \\
\text { previous one }\end{array}$ & $4-28$ \\
\hline S17 & 1 & 1 & 2 & NR & No & 22 \\
\hline 5 & 1 & 2 & 7 & 2 & No & $21-28$ \\
\hline s20 & 2 & 3 & 8 & 3 & No & $10-30$ \\
\hline S21 & 1 & 3 & 3 & 3 & No & $7-8$ \\
\hline S22 & 3 & 4 & 51 & NR & No & $4.6-18$ \\
\hline 4 & 9 & 20 & 53 & 7 & $\begin{array}{l}\text { RR interval }>3 \mathrm{~s} \text { and } \geq 2 \text {-fold as the } \\
\text { previous one }\end{array}$ & $3.9-26$ \\
\hline S24 & 1 & 1 & 5 & NR & No & 19 \\
\hline S25 & 1 & 2 & 2 & NR & No & $22-29$ \\
\hline 3 & 10 & 24 & 86 & 23 & $\mathrm{RR}$ interval $>3 \mathrm{~s}$ & 3-33 \\
\hline S27 & 1 & 3 & 3 & 3 & No & 24-38 \\
\hline S28 & 1 & 1 & 3 & 1 & No & 20 \\
\hline Total & 80 & 182 & 537 & 100 & $6 / 28$ & \\
\hline
\end{tabular}

Abbreviations: IA = ictal asystole; NR = not reported; sIA = reported symptomatic ictal asystole.

${ }^{a}$ For full references, see supplemental material.

${ }^{b}$ With at least 1 ictal asystole and more than 1 seizure simultaneously recorded with EEG and ECG.

${ }^{\mathrm{c}}$ One IA was excluded due to a duration of 2 seconds. 
report more than one seizure simultaneously with ECG and EEG, 18 studies had not recorded any IA occurring simultaneously with ECG and EEG, and 14 studies did not report the total number of recorded seizures. Furthermore, 5 case series were removed, because they were subsequently included in larger studies. Finally, 4 cases recorded after implantation of a pacemaker were excluded, because this intervention prevented IA. A total of 28 studies (13 case reports and 15 case series) met the inclusion criteria. In addition, 9 patients from our local database were included in the final analysis after removing duplicates from 2 previously published case series from our center. ${ }^{10,11}$

Included studies and patient characteristics. A total of 80 patients from 28 studies with 182 IAs in 537 seizures simultaneously recorded with ECG and EEG were included (including 9 patients with 15 IAs in 32 seizures from our local database; table 1). Six studies provided a precise definition of IA. Table 2 summarizes the clinical data of the included patients.

Recurrence risk of IA and potential influencing factors. On average, the short-term recurrence risk of IA amounted to $40.4 \%$ ( $95 \%$ confidence interval [CI] $32.4 \%-49.8 \%$ ). This result was verified by the random-effects meta-analysis, which yielded a similar short-term IA recurrence risk of $43.7 \%$ (95\% CI $34.2 \%-53.7 \%$ ). When considering the local dataset only (for which information on chronological order of IA occurrence was available and that allowed exclusion of seizures prior to the index IA), IA recurrence risk was estimated as 30\% (95\% CI 14\%-53\%) (see table e-1 at Neurology.org for more detailed analysis).

The recurrence risk of IA seemed to decrease with the total number of recorded seizures per patient (figure 2A). None of the clinical factors (age, sex, type and duration of epilepsy, hemispheric lateralization, duration of IA per patient) appeared to have a significant effect on the recurrence risk of IA (table 2). Figure 2B shows the distribution of the number of IA vs the total number of recorded seizures per patient. Importantly, information on whether IA was symptomatic (i.e., associated with syncope) was given in 60 patients with 398 seizures (table 1 ). In these 60 patients, a total of 142 IAs occurred, of which 100 were symptomatic. The proportion of symptomatic vs asymptomatic IA in those with recurring IA amounted to $63.8 \%$ (95\% CI $55.7 \%-72.8 \%)$.

DISCUSSION The exact mechanism of IA is not fully understood, but may be due to involvement of

\begin{tabular}{|c|c|c|c|c|c|}
\hline Summary data of clinical & characteristics & & & & \\
\hline Variable & Mean \pm SD & OR $(95 \% \mathrm{Cl})^{\mathrm{a}}$ & p Value ${ }^{a}$ & OR $(95 \% \mathrm{Cl})^{\mathrm{b}}$ & $p$ Value $^{b}$ \\
\hline Age, y & $40.1 \pm 15.7$ (9 NR) & $1.01(0.99-1.04)$ & 0.34 & $1.01(0.99-1.03)$ & 0.17 \\
\hline Duration of epilepsy, $y$ & $17.1 \pm 14.7$ (11 NR) & $0.99(0.96-1.02)$ & 0.46 & $0.99(0.97-1.02)$ & 0.70 \\
\hline Average asystole duration per patient, $s$ & $15.8 \pm 13.3(12 \mathrm{NR})$ & $1.01(0.96-1.05)$ & 0.78 & $1.01(0.98-1.04)$ & 0.38 \\
\hline \multicolumn{6}{|l|}{ No. of patients ${ }^{c}$} \\
\hline \multicolumn{6}{|l|}{ Sex } \\
\hline Female $^{d}$ & 31 & & & & \\
\hline Male & 40 & $0.98(0.42-2.27)$ & 0.97 & $1.39(0.72-2.69)$ & 0.33 \\
\hline NR & 9 & & & & \\
\hline \multicolumn{6}{|l|}{ Epilepsy type } \\
\hline Temporal lobe epilepsy ${ }^{d}$ & 60 & & & & \\
\hline Extratemporal lobe epilepsy & 9 & $1.84(0.52-6.55)$ & 0.34 & $0.86(0.33-2.26)$ & 0.76 \\
\hline NR & 11 & & & & \\
\hline \multicolumn{6}{|l|}{ Hemispheric lateralization } \\
\hline Left $^{d}$ & 28 & & & & \\
\hline Right & 23 & $1.20(0.53-2.71)$ & 0.66 & $0.71(0.33-1.52)$ & 0.38 \\
\hline Bilateral & 14 & $2.23(0.84-5.90)$ & 0.11 & $1.49(0.62-3.56)$ & 0.37 \\
\hline NR & 15 & & & & \\
\hline
\end{tabular}

Abbreviations: $\mathrm{Cl}=$ confidence interval; $\mathrm{NR}=$ not reported; $\mathrm{OR}=$ odds ratio.

${ }^{a}$ According to the full model with all variables (complete cases $n=38$ ).

${ }^{b}$ Each variable tested separately corrected for the variable seizure count (for age, $n=71$; for duration of epilepsy, $n=69$; for mean asystole duration per patient, $n=68$; for sex, $n=71$; for epilepsy type, $n=69$; for hemispheric lateralization, $\mathrm{n}=65)$.

${ }^{\mathrm{c}}$ Total number of patients $=80$.

${ }^{\mathrm{d}}$ Reference levels of the model. 

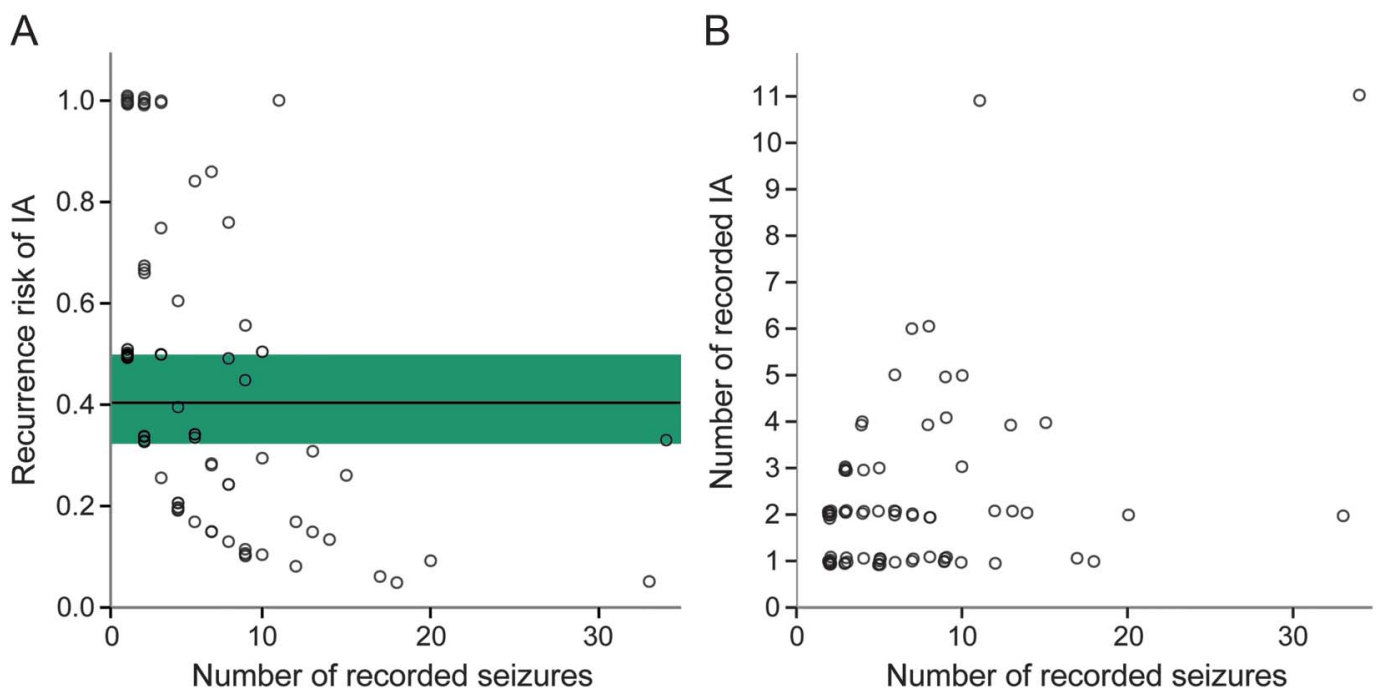

(A) Individual recurrence risk of IA is plotted vs the total number of recorded seizures per patient. A jitter was used to avoid overplotting. The black line indicates the estimated average recurrence risk of IA with the $95 \%$ confidence interval (blue rectangle). (B) Individual number of IAs is plotted vs the total number of recorded seizures per patient.

the central autonomic network, which controls the parasympathetic and sympathetic output, or alternatively involvement of vasovagal reflex pathways. ${ }^{1,15}$ We did not find any correlation between side of seizure onset and occurrence of IA or recurrence risk. We found that in cases of recorded IA during videoEEG telemetry, the recurrence risk of IA varied from patient to patient (figure 3A), but amounted to $40 \%$ on average. This result was verified by the regular meta-analysis. The small difference in the estimate and CI can be explained by the different method and the additional clustering structure for the variable studies. However, testing the additional random effect for the variable studies in the random mixed effect logistic regression model did not improve the model fit. Therefore, we used the simpler model with a random effect for the variable patients only. None of the studied clinical features predicted an increased recurrence risk of IA.

Our study has some limitations. First, patient and seizure characteristics were only partially reported in the included articles. This possibly reduces the power to detect a significant effect on the recurrence of IA outcome. Therefore, we cannot rule out that we have

Figure 3 Histograms of the individual recurrence risk of ictal asystole (IA) and of mean IA duration per patient
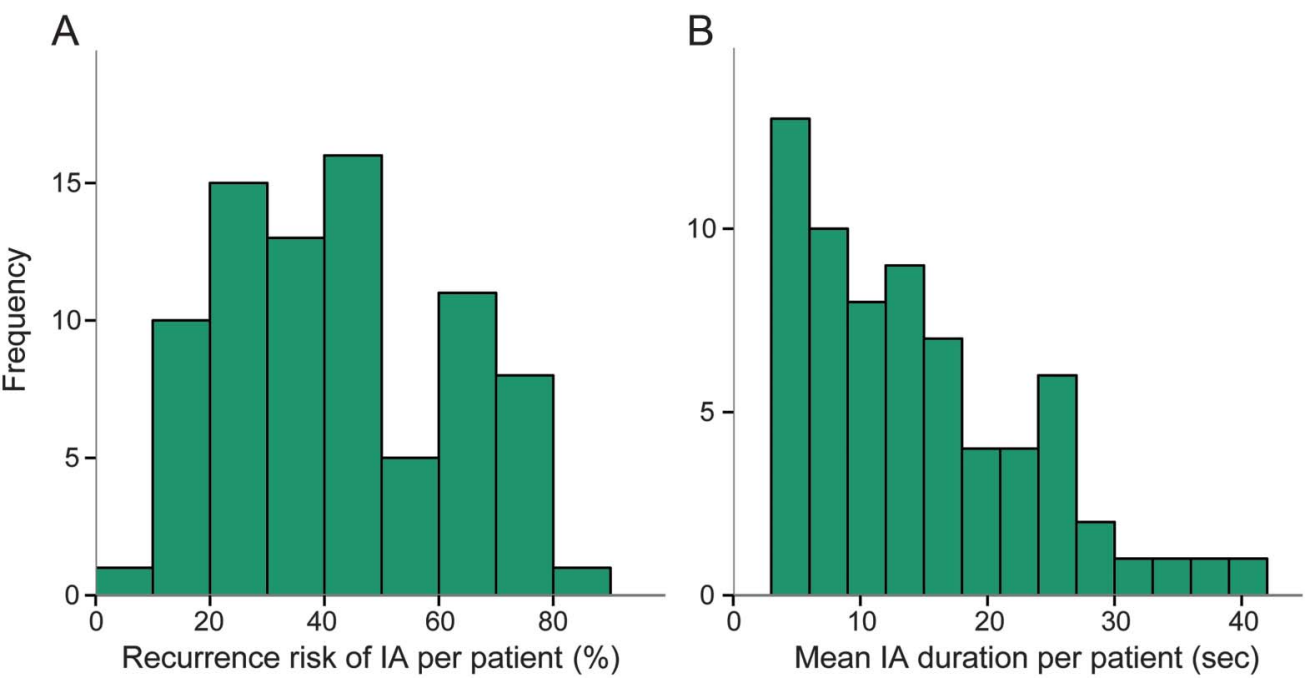

(A) The individual IA recurrence risk (as calculated by the model in \%, bin size 10\%) is plotted vs the absolute frequencies. (B) The mean IA duration per patient (in seconds; bin size 3 seconds) is plotted vs the absolute frequencies. One observation with an IA of 96 seconds is not included in the graph. 
overlooked weak to moderate effects of potential influencing factors. Second, we included studies with different definitions of IA or studies that lacked one (table 1)..$^{-4,6,16}$ Because information on the duration of IA was missing, we could not verify in all reported IA which definition was used. However, the summary data showed that most IA lasted longer than 4 seconds and thus met all definition criteria for IA (table 2 and figure $3 \mathrm{~B}$ ). In addition, of all studies that provided information on seizure characteristics, only one asystole had to be excluded due to duration of only 2 seconds. Thus, the lack of definition of IA in most studies had no major influence on our results. Third, an effect of anticonvulsants and their reduction during the monitoring period on the risk of recurrence of IA cannot be ruled out. Furthermore, publication bias may be present. For example, one may expect that cases with higher recurrence risk are more likely to be reported. This might be particularly true for case reports in which only severe seizure-related syncope are described. We assessed this issue by separately analyzing recurrence risk of IA in patients from our local database, yielding a recurrence risk of $53.7 \%(95 \%$ CI $28.2 \%-77.4 \%$ ), which is even higher than the estimated risk of the composite data. This finding argues against an overestimation due to publication bias. Another legitimate concern is the lack of information on the chronological order of the seizures with and without IA in most published cases. Therefore, we estimated the recurrence risk both by including and by excluding the index seizure with IA in all seizures and in the seizures from the local database only (table e-1). Importantly, the most conservative calculation yielded an IA recurrence risk of $30 \%$ (95\% CI 14\%-53\%), which largely overlaps with the estimation including all available seizures, suggesting that our results are plausible. In this context, it is also important to note that the included reports did not consistently provide information on whether IA was asymptomatic or whether IA was associated with clinical symptoms or syncope. Thus, given the smaller number of reported symptomatic IAs, we are unable to calculate a valid estimation of the recurrence risk of IA-related syncope. Furthermore, temporal lobe epilepsy is likely to be overrepresented in the analyzed studies, because it is more frequently investigated with video-EEG monitoring in an epilepsy surgery setting. Finally, the apparent recurrence risk of IA seems to decrease with higher number of recorded seizures (figure 1B). Patients with fewer seizures recorded tended to have a higher risk than those in whom more seizures were recorded. In addition, in most patients only a few seizures per patient were recorded. Thus, one might think that this study could overestimate the risk of recurrence of IA. However, this observation is most probably not directly related to the total number of seizures recorded, but more likely due to patient selection: in patients with higher risk of IA, physicians were less likely to have recorded more seizures. Instead, these patients would have been referred to cardiology for pacemaker implantation. Taken together, we believe that our study population represents a rather typical mixture of patients with refractory epilepsy seen at specialized epilepsy centers.

The short-term recurrence risk of IA is high and amounts to $40 \%$, therefore requiring special attention. In people in whom seizures cannot be fully controlled by anticonvulsant drugs or alternative treatments (e.g., epilepsy surgery), implantation of a cardiac pacemaker seems advisable to prevent syncope-related injuries. ${ }^{3,6}$ In people in whom IA is suspected, our data suggest that the recording of 1 or 2 seizures is not sufficient to rule out IA. If prolonged inpatient video-EEG monitoring is not available, insertion of an insertable cardiac monitor may be an alternative option.

\section{AUTHOR CONTIBUTIONS}

Kevin G. Hampel: study design, literature search, data acquisition, statistical analysis, interpretation of the data, writing of the manuscript, drafting the figures. Roland D. Thijs: interpretation of the data, revision of the manuscript for important intellectual content. Christian E. Elger: interpretation of the data, revision of the manuscript for important intellectual content. Rainer Surges: study design, literature search, data acquisition, statistical analysis, interpretation of the data, writing of the manuscript, drafting the figures.

\section{ACKNOWLEDGMENT}

The authors thank Guido Lüchters, PhD (statistician from the Centre for Development Research, University of Bonn, Germany), for support with statistical analysis, and Leila Chaieb, $\mathrm{PhD}$, Marcin Leszczynski, $\mathrm{PhD}$, and Amirhossein Jahanbekam, MSc, for discussion and help with $\mathrm{R}$ programming.

\section{STUDY FUNDING}

No targeted funding reported.

\section{DISCLOSURE}

K. Hampel has received support from Cyberonics and fees as speaker from Eisai. R. Thijs receives research support from the Dutch National Epilepsy Fund, NUTS Ohra Fund, Medtronic, ZonMW, and AC Thomson Foundation, and has received fees for lectures from Medtronic, UCB, and GSK. C. Elger has served as a paid consultant for UCB Pharma, Desitin, and Pfizer and has received speaker fees from Eisai, Novartis, and UCB Pharma. He is an employee of the Life and Brain Institute Bonn. R. Surges has received fees as speaker or consultant from Bial, $\mathrm{Cy}$ beronics, Desitin, Eisai, Novartis, and UCB Pharma. Go to Neurology. org for full disclosures.

Received December 14, 2016. Accepted in final form April 20, 2017.

\section{REFERENCES}

1. van der Lende M, Surges R, Sander JW, Thijs RD. Cardiac arrhythmias during or after epileptic seizures. J Neurol Neurosurg Psychiatry 2016;87:69-74.

2. Nguyen-Michel VH, Adam C, Dinkelacker V, et al. Characterization of seizure-induced syncopes: EEG, ECG, and clinical features. Epilepsia 2014;55:146-155 
3. Strzelczyk A, Cenusa M, Bauer S, et al. Management and long-term outcome in patients presenting with ictal asystole or bradycardia. Epilepsia 2011;52:1160-1167.

4. Schuele SU, Bermeo AC, Alexopoulos AV, et al. Videoelectrographic and clinical features in patients with ictal asystole. Neurology 2007;69:434-441.

5. Rossetti AO, Dworetzky BA, Madsen JR, et al. Ictal asystole with convulsive syncope mimicking secondary generalisation: a depth electrode study. J Neurol Neurosurg Psychiatry 2005;76:885-887.

6. Moseley BD, Ghearing GR, Munger TM, Britton JW. The treatment of ictal asystole with cardiac pacing. Epilepsia 2011;52:e16-19.

7. Ghearing GR, Munger TM, Jaffe AS, et al. Clinical cues for detecting ictal asystole. Clin Auton Res 2007;17:221-226.

8. Moher D, Liberati A, Tetzlaff J, et al. Preferred reporting items for systematic reviews and meta-analyses: the PRISMA statement. Ann Intern Med 2009;151:264-269. W64.

9. Schardt C, Adams MB, Owens T, et al. Utilization of the PICO framework to improve searching PubMed for clinical questions. BMC Med Inform Decis Mak 2007;7:16.
10. Kowalik A, Bauer J, Elger CE. Asystolic seizures. Nervenarzt 1998;69:151-157.

11. Rocamora R, Kurthen M, Lickfett L, et al. Cardiac asystole in epilepsy: clinical and neurophysiologic features. Epilepsia 2003;44:179-185.

12. von Elm E, Altman DG, Egger M, et al. The Strengthening the Reporting of Observational Studies in Epidemiology (STROBE) statement: guidelines for reporting observational studies. Lancet 2007;370:1453-1457.

13. Bolker BM, Brooks ME, Clark CJ, et al. Generalized linear mixed models: a practical guide for ecology and evolution. Trends Ecol Evol 2009;24:127-135.

14. Lyman GH, Kuderer NM. The strengths and limitations of meta-analyses based on aggregate data. BMC Med Res Methodol 2005;5:14.

15. Palma J-A, Benarroch EE. Neural control of the heart: recent concepts and clinical correlations. Neurology 2014;83:261-271.

16. Bestawros M, Darbar D, Arain A, et al. Ictal asystole and ictal syncope: insights into clinical management. Circ Arrhythm Electrophysiol 2015;8:159-164.

\section{Committed to Making a Difference: 2018 American Academy of Neurology Research Program}

The American Academy of Neurology (AAN) is committed to making a profound difference in the lives of researchers, in turn making a difference in the lives of patients with brain disease. The ambitious 2018 AAN Research Program offers 19 opportunities, ranging from $\$ 130,000$ to $\$ 450,000$ and designed for all types of research across all career levels and discovery stages. Pave your own pathway to patient care by applying for one of the five new awards or 14 other disease-specific and non-disease-specific opportunities by the October 1, 2017, deadline. Visit AAN.com/view/ ResearchProgram today.

\section{Pet Neurology.org Offers Important Information to Patients and Their Families}

The Neurolog ${ }^{\circledR}$ Patient Page provides:

- A critical review of ground-breaking discoveries in neurologic research that are written especially for patients and their families

- Up-to-date patient information about many neurologic diseases

- Links to additional information resources for neurologic patients

All Neurology Patient Page articles can be easily downloaded and printed, and may be reproduced to distribute for educational purposes. Click on the 'Patients' link on the home page (Neurology.org) for a complete index of Patient Pages. 


\section{Neurology}

Recurrence risk of ictal asystole in epilepsy

Kevin G. Hampel, Roland D. Thijs, Christian E. Elger, et al.

Neurology 2017;89;785-791 Published Online before print July 26, 2017

DOI 10.1212/WNL.0000000000004266

This information is current as of July 26, 2017

\section{Updated Information \& Services}

\section{Supplementary Material}

\section{References}

Citations

Subspecialty Collections

Permissions \& Licensing

\section{Reprints}

including high resolution figures, can be found at: http://n.neurology.org/content/89/8/785.full

Supplementary material can be found at: http://n.neurology.org/content/suppl/2017/07/26/WNL.0000000000004 266.DC1

http://n.neurology.org/content/suppl/2017/07/26/WNL.0000000000004 266.DC2

This article cites 16 articles, 5 of which you can access for free at: http://n.neurology.org/content/89/8/785.full\#ref-list-1

This article has been cited by 4 HighWire-hosted articles: http://n.neurology.org/content/89/8/785.full\#\#otherarticles

This article, along with others on similar topics, appears in the following collection(s):

All Epilepsy/Seizures

http://n.neurology.org/cgi/collection/all_epilepsy_seizures Epilepsy monitoring http://n.neurology.org/cgi/collection/epilepsy_monitoring _

Information about reproducing this article in parts (figures,tables) or in its entirety can be found online at:

http://www.neurology.org/about/about_the_journal\#permissions

Information about ordering reprints can be found online: http://n.neurology.org/subscribers/advertise

Neurology ${ }^{\circledR}$ is the official journal of the American Academy of Neurology. Published continuously since 1951, it is now a weekly with 48 issues per year. Copyright Copyright ( 2017 The Author(s). Published by Wolters Kluwer Health, Inc. on behalf of the American Academy of Neurology.. All rights reserved. Print ISSN: 0028-3878. Online ISSN: 1526-632X.

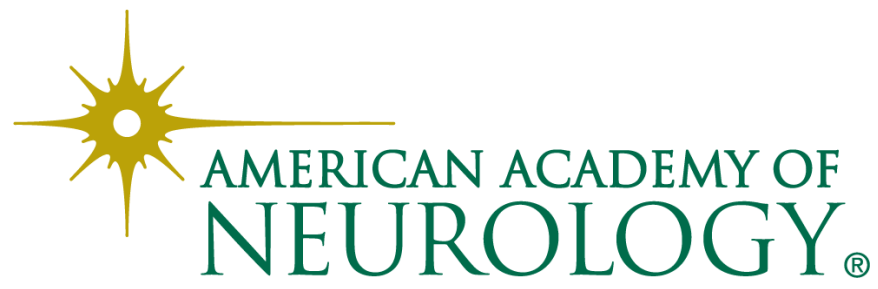

